Copyright (C) 2015 by Academic Publishing House Researcher

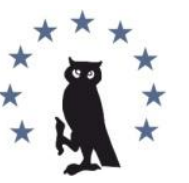

Published in the Russian Federation

European Researcher

Has been issued since 2010.

ISSN 2219-8229

E-ISSN 2224-0136

Vol. 90, Is. 1, pp. 17-25, 2015

DOI: $10.13187 /$ er.2015.90.17

www.erjournal.ru



Economic sciences

Экономические науки

UDC 338.48

\title{
Trends in the Development of International Tourism and Imperatives of Modernizing the Tourism Industry
}

\author{
Zeyneb Adamanova
}

Crimean Engineering and Pedagogical University, Russian Federation 295015, Republic of Crimea, Simferopol, Sevastopolskaya Str., Uchebny av., 8 Doctor (Economics), professor

E-mail: azo2005edie@mail.ru

\begin{abstract}
This article provides a rationale for the significance and explores the characteristics of international tourism. The author establishes that this sector of the global economy has been developing in quite a sustainable fashion, without being affected by substantial differences between various regions around the world. The author discusses groups of stimulating factors and major trends in the development of international tourism at the current stage, including major changes in the tourism product and the operation of the global market of tourism services. The article defines the imperatives of modernizing the tourism industry at the national level.

Keywords: international tourism; tourism industry.

\section{Введение}

Международный туризм, сформировавшийся как явление в последние десятилетия, в начале XXI века образовал одну из наиболее динамичных и доходных отраслей мировой экономики. Постоянно увеличивается доля туризма как формы международной торговли услугами. Интенсивное развитие международного туризма сопровождается возникновением новых тенденций, которые должны учитываться при разработке государственной политики в сфере туризма.

Интенсивное развитие международного туризма во многих странах оказало большое влияние на экономический рост, повышение уровня занятости, позволило увеличить бюджетные поступления и решать экологические проблемы. При большом разнообразии современного туризма его роль постоянно расширяется. В связи с этим многие страны ставят задачу обеспечить ускоренное и сбалансированное развитие туристической индустрии, для определения императивов и направлений развития которой необходим учет мировых тенденций и последствий глобализации.
\end{abstract}




\section{Обсуждение}

В последние годы внимание к международному туризму постоянно увеличивается вследствие его бурного развития. С. Радаев рассматривает международный туризм как составляющую системы современных международных отношений. Автор выделяет виды и факторы развития международного туризма, исследует соответствующий мировой рынок и систему регулирования. Рассмотрено влияние международного туризма на национальную экономику, а также общемировые и региональные аспекты его развития [1]. С. Пономарева исследует международный туризм как форму внешнеэкономической деятельности региона, что также подтверждает большую роль в развитии национальной экономики [2].

Исследованию тенденций развития международного туризма на глобальном уровне посвящены работы: И. Гараньи [3], О. Лозовой [4], Н. Полещука [5], С. Чернецкой [6]. Эти труды демонстрируют глубокие преобразования туристической отрасли на мировом уровне, появление новых тенденций и закономерностей ее развития. Обобщив результаты этих исследований, можно на новом уровне оценить конъюнктуру и направления трансформаций системы международного туризма. Также необходимо выделить и некоторые угрозы, которые блокируют его развитие. А. Адамеску рассматривает аспекты интеграции российской туристической индустрии в систему международного туризма, учитывая ее изменения [7]. Все это позволяет определить направления модернизации туристической инфраструктуры, что предполагает широкое использование мирового опыта $[8,10]$.

Цель исследования: выделить основные тенденции развития международного туризма и определить императивы модернизации туристической индустрии на национальном уровне.

Изложение основного материала. Прежде всего, необходимо отметить, что в настоящей работе речь пойдет о глобальных тенденциях, отражающих основные направления трансформации системы международного туризма, мирового рынка туристических услуг и соответствующей инфраструктуры. Тенденции низших порядков, характеризующиеся большим многообразием (учитывая особенности видов туризма, регионов мира, стран и т.п.), заслуживают стать предметом отдельных исследований и прямо зависят от глобальных трендов.

В последние годы аналитические публикации Всемирной туристической организации, являющейся учреждением $\mathrm{OOH} \mathrm{(ЮНВТО),} \mathrm{показывают} \mathrm{ускоренные} \mathrm{темпы} \mathrm{роста}$ международного туризма. В мире его доля по количеству поездок превысила $71 \%$. В большинстве стран международный туризм стал привычным явлением и частью жизни населения (модели потребления). Международный туризм признан одним из важнейших мировых рынков (по обороту и динамике), катализатором экономического роста, экспорта и повышения занятости, экологического развития и совершенствования инфраструктуры на глобальном уровне [9]. Для отдельных стран, преимущественно развивающихся, международный туризм стал ключевым видом экономической деятельности, позволяющим включиться в мировую экономику и бороться с бедностью. Туристические услуги становятся все более и более востребованными, что способствует взаимодействию национальных экономик. В связи с этим развитие международного туризма является предпосылкой стабильного роста мировой экономики. В последние десятилетия это подтвердилось. По интенсивности развития и увеличению доходности международный туризм опережал другие секторы. Превратившись в одну из наибольших экспортных отраслей, туризм играет большую роль в перераспределении совокупного мирового дохода и иностранных инвестиций. При этом международный туризм является экологически безопасным и все более инновационным, способствует диверсификации экономики и развитию сферы услуг и других отраслей.

Международный туризм закономерно является объектом международно-правового регулирования на основе Всеобщей Декларации прав человека и Международного пакта об экономических, социальных и культурных правах. Среди основных международных соглашений и документов в сфере туризма следует выделить: Манильская декларация по мировому туризму, Гаагская декларация по туризму, Общая резолюция Римской конференции ООН по международному туризму и путешествиям, Международные 
гостиничные правила, Кодекс отношений между гостиницами и туристскими агентствами и др. Эти акты на глобальном уровне создают правовой массив, создающий условия для интенсивных туристических потоков, выбор маршрутов и видов путешествий становится все более свободным. Еще больше это выражено на уровне регионов мира в рамках интеграционных объединений.

Разработкой и обеспечением реализации норм регулирования международного туризма занимается ЮНВТО, объединяющая также ряд межправительственных, неправительственных и коммерческих организаций, действующих в сфере туризма и путешествий. Также в мире функционируют специализированные организации, смежные со сферой туризма, в том числе: Международная ассоциация воздушного транспорта, Международная организация гражданской авиации, Азиатско-Тихоокеанская туристическая ассоциация, Международная ассоциация гостиниц и ресторанов и др. Всего в мире насчитывается свыше 200 международных организаций, связанных с туризмом, которые совершенствуют международное право и оказывают поддержку национальным и региональным органам.

Несмотря на отдельные колебания, число международных туристских прибытий по миру демонстрировало практически непрерывный рост: 1950 г. -25 млн., 1980 г. - 278 млн., 1995 г. - 528 млн., 2013 г. - 1087 млн. По оценкам ЮНВТО в 2013 г. международный туризм составил 9 \% мирового ВВП, 9,1 \% рабочих мест, 6 \% мирового экспорта (1,4 трлн. долл. США) и 29 \% экспорта услуг. Выручка, поступившая в турцентры от международных посетителей, достигла 1159 млрд. долл. США. Еще 218 млрд. долл. США выручил международный пассажирский транспорт. ЮНВТО прогнозирует увеличение количества международных туристских прибытий во всем мире до 1,8 трлн. в 2030 г. (в развивающихся странах в среднем на 4,4 \% в год, в развитых - на 2,2 \%). Ожидается, что доля стран с развивающейся экономикой увеличится с 47 \% в 2013 году до 57 \% в 2030 году [9].

Прежде чем рассмотреть современные тенденции, важно выделить факторы, определяющие стремительное развитие международного туризма. Он является сложным социальным явлением, которое имеет оздоровительную, рекреационную, познавательную, гуманитарную, воспитательную и эстетическую направленность. Спрос на туристические услуги постоянно возрастает, что, помимо экономических причин, вызвано изменением культуры, психологии и мировоззрения людей по поводу других стран и народов, единства мира и т.п. У людей возник интерес и даже потребность в туризме, не говоря уже, например, о деловом и образовательном туризме, когда он рассматривается как необходимость. На современном этапе необходимо выделить несколько групп факторов, вызывающих развитие международного туризма: 1) социальные (демографические изменения, рост мобильности, специфическая мотивация, восприятие других стран и народов); 2) экономические (повышение дохода, доступность туристических услуг); 3) инфраструктурные (расширение трансфертной и гостиничной инфраструктуры); 4) экологические (ухудшение экологической ситуации, поиск экономической альтернативы в районах, имеющих рекреационный потенциал); 5) технологические (появление информационных сетей). Также следует учитывать влияние факторов, которые имеют негативное значение, в том числе: военные и социальные конфликты, природные катастрофы, экономические кризисы и культурные противоречия.

После кризиса 2008-2009 гг. практически все процессы и явления рассматриваются через призму его последствий. Тем более это касается туризма, являющегося одной из отраслей наиболее чувствительных к разного рода потрясениям. Влияние кризиса было значительным, поэтому необходимо различать и восстановление отрасли, и краткосрочные конъюнктурные изменения, и долгосрочные структурные тенденции. При этом следует отметить, что международный туризм во многих стран позволил поддержать экономический рост во время кризиса и рецессии, превратился в важнейший (и не требующий больших вложений) двигатель восстановления экономики.

Мировая индустрия туризма развивается достаточно устойчиво (табл. 1). При этом закономерно сохраняется территориальная неравномерность мирового туристического рынка, что объясняется разными уровнями социально-экономического развития стран и регионов. В 2013 г. по регионам мира наблюдалось следующее соотношение международных 
прибытий и поступлений от туризма соответственно: Северная и Южная Америка 168 млн. (15\%) и 229 млрд. долл. США (20\%), Европа - 563 млн. (52\%) и 489 млрд. долл. США (42\%), Азиатско-Тихоокеанский регион - 248 млн. (23\%) и 359 млрд. долл. США (31\%), Средний Восток - 52 млн. (5\%) и 47 млрд. долл. США (4\%), Африка - 56 млн. (5\%) и 34 млрд. долл. США (3\%) [9]. В целом сохраняется зависимость мирового рынка туризма от развитых стран, а его динамика обусловлена увеличением спроса со стороны развивающихся стран.

Таблица 1 Динамика международных туристических прибытий и доля рынка по регионам [9]

\begin{tabular}{|c|c|c|c|c|c|c|c|}
\hline & \multicolumn{5}{|c|}{$\begin{array}{c}\text { Международные туристические } \\
\text { прибытия, млн. }\end{array}$} & \multirow{2}{*}{$\begin{array}{c}\text { Доля } \\
\text { рынка, } \\
\% \\
\end{array}$} & \multirow{2}{*}{$\begin{array}{c}\text { Средний } \\
\text { годовой рост в } \\
2005 / 13 \text { гг. } \\
\end{array}$} \\
\hline & 2000 & 2005 & 2010 & 2012 & 2013 & & \\
\hline Мир в целом & 677 & 807 & 948 & 1035 & 1087 & 100 & 3,8 \\
\hline Развитые страны & 421 & 459 & 506 & 551 & 581 & 53,4 & 3,0 \\
\hline Развивающиеся страны & 256 & 348 & 442 & 484 & 506 & 46,6 & 4,8 \\
\hline \multicolumn{8}{|l|}{ По регионам: } \\
\hline Европа & 388,2 & 448,9 & 484,8 & 534,4 & 563,4 & 51,8 & 2,9 \\
\hline $\mathrm{ATP}^{*}$ & 110,1 & 153,5 & 204,9 & 233,5 & 248,1 & 22,8 & 6,2 \\
\hline Америка** & 128,2 & 133,3 & 150,6 & 162,7 & 167,9 & 15,5 & 2,9 \\
\hline Африка & 26,2 & 34,8 & 49,9 & 52,9 & 55,8 & 5,1 & 6,1 \\
\hline Средний Восток & 24,1 & 36,3 & 58,2 & 51,7 & 51,6 & 4,7 & 4,5 \\
\hline
\end{tabular}

* Азиатско-Тихоокеанский регион;

** Северная и Южная

Структура выездного туризма по целям визита в 2013 г. выглядела следующим образом: 1) досуг, отдых и праздники - 52 \%; 2) здоровье, религия, другое - $27 \%$; 3) бизнес и профессиональная деятельность - 14 \% 4) не специфицировано - 7 \% [9].

Международный туризм является высокодоходной отраслью. При этом распределение доходов также является неравномерным по регионами (табл. 2)

Динамика поступлений от международного туризма по регионам мира [9]

Таблица 2

\begin{tabular}{|l|c|c|c|c|c|c|}
\hline & \multicolumn{2}{|c|}{$\begin{array}{l}\text { Поступления от международного } \\
\text { туризма* в \% (2010-2013 гг.) }\end{array}$} & \multicolumn{2}{c|}{$\begin{array}{c}\text { Доля } \\
\text { рынка в }\end{array}$} & \multicolumn{2}{c|}{$\begin{array}{l}\text { Поступления, } \\
\text { млрд. долл. США }\end{array}$} \\
\cline { 2 - 4 } & $2011 / 2010$ & $2012 / 2011$ & $2013 / 2012$ & 2013 г., \% & 2012 г. & 2013 г. \\
\hline Мир в целом & 4,5 & 4,2 & 5,3 & 100 & 1078 & 1159 \\
\hline Развитые страны & 5,9 & 4,0 & 6,0 & 64,3 & 688 & 745 \\
\hline $\begin{array}{l}\text { Развивающиеся } \\
\text { страны }\end{array}$ & 2,1 & 4,5 & 4,0 & 35,7 & 390 & 413 \\
\hline По регионам: & & & & & & \\
\hline Европа & 4,9 & 1,9 & 3,8 & 42,2 & 454,0 & 489,3 \\
\hline АТР & 8,3 & 6,7 & 8,2 & 31,0 & 329,1 & 358,9 \\
\hline Америка & 5,1 & 5,7 & 6,4 & 19,8 & 212,9 & 229,2 \\
\hline Африка & 1,7 & 7,3 & 0,0 & 3,0 & 34,3 & 34,2 \\
\hline Средний Восток & $-17,2$ & 2,2 & $-1,9$ & 4,1 & 47,5 & 47,3 \\
\hline
\end{tabular}

* местные валюты, текущие цены

Развитые страны получают большую часть доходов за счет международного туризма. В основном это страны Европы, за которой сохраняется статус мирового туристического лидера. В то же время значительная позитивная динамика наблюдается по АзиатскоТихоокеанскому региону, который демонстрировал большой приток международных туристов. 
Таблица 3

Динамика международных туристических прибытий по регионам происхождения [9]

\begin{tabular}{|l|c|c|c|c|c|}
\hline \multirow{2}{*}{} & \multicolumn{5}{|c|}{ Международные туристические прибытия, млн. } \\
\cline { 2 - 6 } & 2000 г. & 2005 г. & 2010 г. & 2012 г. & 2013 г. \\
\hline Мир в целом, в т.ч. из: & 677 & 807 & 948 & 1035 & 1067 \\
\hline Европа & 388,8 & 449,7 & 496,6 & 537,3 & 565,9 \\
\hline АТР & 114,2 & 153,2 & 206,3 & 237,2 & 250,3 \\
\hline Америка & 130,8 & 135,5 & 156,3 & 171,6 & 178,1 \\
\hline Средний Восток & 14,1 & 22,9 & 34,5 & 31,6 & 32,3 \\
\hline Африка & 14,9 & 19,3 & 28,3 & 31,9 & 33,4 \\
\hline Не специфицировано & 14,1 & 25,4 & 26,3 & 25,7 & 26,8 \\
\hline
\end{tabular}

Практически по всем регионам мира наблюдается позитивная динамика, которая зависит от роста доходов населения. Зависимость от доходов проявляется повсеместно и практически не связана с культурными и другими факторами, что свидетельствует об уровне развития мирового туристического рынка. В последние годы первенство на этом рынке сохраняют «традиционные» туристические лидеры. В 2013 г. по индексу конкурентоспособности сектора путешествий и туризма первая 20-ка стран выглядела так: Швейцария, Германия, Австрия, Испания, Великобритания, США, Франция, Канада, Швеция, Сингапур, Австралия, Новая Зеландия, Нидерланды, Китай, Гонконг, Исландия, Финляндия, Бельгия, Ирландия, Португалия, Дания, Норвегия, Люксембург, альта, Южная Корея, Италия (по оценкам Всемирного экономического форума). Первая десятка стран по количеству международных туристических прибытий и поступлений представлена в табл. 4.

Страны-лидеры по количеству международных туристических прибытий

Таблица 4 и объему поступлений [9]

\begin{tabular}{|c|c|c|c|c|c|c|c|}
\hline \multirow[t]{2}{*}{ Ранг } & \multirow[t]{2}{*}{ Страны } & \multicolumn{2}{|c|}{$\begin{array}{c}\text { Международные } \\
\text { туристические } \\
\text { прибытия, млн. }\end{array}$} & \multirow[t]{2}{*}{ Ранг } & \multirow[t]{2}{*}{ Страны } & \multicolumn{2}{|c|}{$\begin{array}{c}\text { Поступления от } \\
\text { международного } \\
\text { туризма, млрд. } \\
\text { долл. США }\end{array}$} \\
\hline & & 2012 г. & 2013 г. & & & 2012 г. & 2013 г. \\
\hline 1. & Франция & 83,0 & - & 1. & США & 126,2 & 139,6 \\
\hline 2. & США & 66,7 & 69,8 & 2. & Испания & 56,3 & 60,4 \\
\hline 3. & Испания & 57,5 & 60,7 & 3. & Франция & 53,6 & 56,1 \\
\hline 4. & Китай & 57,7 & 55,7 & 4. & Китай & 50,0 & 51,7 \\
\hline 5. & Италия & 46,4 & 47,7 & 5. & Макао & 43,7 & 51,6 \\
\hline 6. & Турция & 35,7 & 37,8 & 6. & Италия & 41,2 & 43,9 \\
\hline 7. & Германия & 30,4 & 31,5 & 7. & Таиланд & 33,8 & 42,1 \\
\hline 8. & Великобритания & 29,3 & 31,2 & 8. & Германия & 38,1 & 41,2 \\
\hline 9. & Россия & 25,7 & 28,4 & 9. & Великобритания & 36,2 & 40,6 \\
\hline 10. & Таиланд & 22,4 & 26,5 & 10. & Гонконг & 33,1 & 38,9 \\
\hline
\end{tabular}

В лидеры по потреблению туристических услуг выходят новые страны. По данным ЮНВТО первая десятка потребителей выглядит так (2012 и 2013 г. соответственно в млрд. долл. США, а также доля рынка в \%): 1) Китай - 102,0 и 128,6 (11,1\%); 2) США - 83,5 и $86,2(7,4 \%) ; 3)$ Германия - 81,3 и 85,9 (7,4\%); 4) Россия - 42,8 и 53,5 (4,6\%); 5) Великобритания - 51,3 и 52,6 (4,5\%); 6) Франция - 39,1 и 42,4 (3,7\%); 7) Канада - 35,0 и 35,2 (3,0\%); 8) Австралия - 28,0 и 28,4 (2,4\%); 9) Италия - 26,4 и 27,0 (2,3\%); 10) Бразилия 22,2 и 25,1 (2,2\%) [9]. Появление новых стран-потребителей, характеризующихся повышением доходов населения при значительной демографии (Китай, Россия, Бразилия) создает основу для дальнейшей позитивной динамики. 
Представленные данные дают основания говорить о смещении акцентов и центров развития международного туризма от традиционных рынков Западной Европы и США к альтернативным рынкам (Центральная и Восточная Европа, Китай, Южная Корея, Мексика, Ближний Восток).

Улучшение конъюнктуры мирового рынка туристических услуг сопровождается некоторыми качественными преобразованиями, связанными с его консолидацией и интенсификацией туристических потоков.

Во-первых, становление мирового туристического рынка сопровождается процессами транснационализации, движений международных инвестиций, усилением связей между фирмами разных стран. Также более активно протекают интеграционные процессы в секторе туризма (горизонтальная и вертикальная интеграция), в том числе на международном уровне (преимущественно путем слияния или поглощения однородных по бизнесу или смежных компаний). Например, путем слияния происходит распространение по различным странам мира гостиничных цепочек «Sheraton», «Mariotte», «Novotel», «Sofitel», «Hilton» и др. В 2012-2013 гг. усилились интеграционные процессы между туристическим и транспортным сектором [9].

Во-вторых, высокие темпы роста туристического сектора сопровождаются обновлением его структуры за счет возникновения новых видов туризма (приключенческий, культурно-познавательный, исследовательский, деловой, космический), услуг (основные, дополнительные, сопутствующие), маршрутов, технологий обслуживания и т.п. Существенно повышается значимость инноваций и влияния фактора НТП.

B-третьих, постоянно повышаются требования к качеству туристических услуг, в том числе к сервису и безопасности. При этом следует учитывать, что в мире преобладают индивидуальные туристы (70-80 \%), туризм с целью рекреации с увеличением продолжительности пребывания. Международные туристы существенно отличаются по культуре, менталитету. Это требует создания комбинированных туристических продуктов (например, культурно-познавательно-развлекательного), а также особых условий (размещения, перевозки, питания, программы поездки и пр.), учитывающих их этнические и культурные особенности.

B-четвертых, при постоянном ужесточении конкуренции на мировом рынке туристических услуг, открываются новые маршруты. Увеличивается пространственный разброс туристических потоков, которые становятся все более интрарегиональными. При этом туристическое предложение становится перенасыщенным и превышает спрос.

B-пятых, происходит диверсификация видов туризма по различным признакам как на традиционных, так и новых рынках. Интенсивно развивается коммерческий и социальный туризм. Происходит углубление специализации фирм и центров туризма. По различным видам туризма происходит усложнение туристического продукта и появление его новых разновидностей.

B-шестых, международный туризм более активно развивается в рамках интеграционных группировок, где создаются благоприятные условия, формируется единый рынок туристических услуг и облегчается мобильность населения. К таким группировкам относятся, прежде всего, ЕС, КАРИКОМ и АСЕАН. Кроме этого вопросами развития международного туризма занимаются такие организации, как: НАФТА, МЕРКОСУР, Организация Черноморского экономического сотрудничества, СНГ.

B-пятых, глобальное значение для развития туризма приобретают города. Прежде всего, это касается ведущих городов мира, являющихся мировыми финансовыми, торговыми и культурными центрами. По экспертным оценкам наиболее привлекательными являются: Дублин, Лондон, Париж, Эдинбург, Берлин, Франкфурт, Венна, Москва, Цюрих, Прага, Милан, Рим, Барселона, Женева, Лиссабон, Амстердам, Брюссель, Мадрид.

Новые вызовы развития международного туризма создают: появление новых угроз безопасности, дифференциацию туристов (по культуре, доходу, образованию и т.п.), старение населения, прогресс технологий, ускорение темпов урбанизации, изменение климата. В этой связи на национальном уровне возникает необходимость качественного изменения предложения туристических услуг и модернизации туристической индустрии по глобальным императивам (табл. 5). 
Императивы модернизации туристической инфраструктуры страны

\begin{tabular}{|c|c|}
\hline Императив & Характеристика и направления модернизации \\
\hline Инноватизация & $\begin{array}{l}\text { предполагает повышение инновационной активности во всех сферах } \\
\text { привлечения и обслуживания международных туристов и реализацию } \\
\text { новейших мировых достижений и опыта, совершенствование всех } \\
\text { компонентов инфраструктуры; проявляется в выпуске новых видов } \\
\text { туристского продукта; использование новой техники и технологии, } \\
\text { туристских ресурсов, изменения в организации сервиса и потребления; } \\
\text { новый маркетинг и менеджмент; выявление новых рынков }\end{array}$ \\
\hline Экол & $\begin{array}{l}\text { предполагает уменьшение нагрузки на окружающую среду, увеличение } \\
\text { вклада в ее защиту, распространение соответствующих ценностей; } \\
\text { проявляется во внедрении инноваций соответствующей направленности } \\
\text { и новых стандартов обслуживания и отдыха туристов }\end{array}$ \\
\hline Социа & $\begin{array}{l}\text { предполагает сближение частных и общественных потребностей, более } \\
\text { полное и разностороннее удовлетворение потребностей туристов; } \\
\text { проявляется в осуществлении социально ориентированных } \\
\text { трансформаций туристической деятельности, внедрении сетевых } \\
\text { сервисов, создании индивидуализированного туристского продукта; } \\
\text { реформирование гостиничных и ресторанных цепочек обслуживания }\end{array}$ \\
\hline
\end{tabular}

Реализация этих императивов предполагает активизацию государственной политики в сфере туризма, осуществление дополнительного стимулирования предприятий отрасли при соблюдении условий рыночной конкуренции. При этом государственное регулирование должно быть направлено не только на улучшение материальных основ, но и на изменение структуры туристических потоков. Для стимулирования может быть использован широкий арсенал методов стимулирования туристического сектора, известных из мировой практики. Специальная поддержка государства должна включать: предоставление налоговых, кредитных, земельных, тарифных льгот, бюджетное финансирование инфраструктурных и образовательных проектов. Эти методы должны приобрести модернизационную функцию, соблюдая представленные императивы.

\section{Заключение}

Тенденции развития современного международного туризма дают странам ориентиры и возможности для модернизации туристической индустрии. При эффективной политике в сфере туризма это будет иметь позитивные макроэкономические эффекты. Отдельное внимание следует уделять вопросам повышения открытости туристической индустрии.

\section{Примечания:}

1. Раднаев С.Б. Международный туризм в системе современных международных экономических отношений / С.Б. Раднаев; дис. ... канд. экон. наук: 08.00.14. Москва, 2001. $159 \mathrm{c}$.

2. Пономарева С.Ю. Международный туризм как форма внешнеэкономической деятельности региона (на примере Ростовской области) / С.Ю. Пономарева; дис. ... канд. экон. наук: 08.00.14. Ростов-на-Дону, 2004. 205 с.

3. Гаранья И. Тенденции развития международного туризма [Электронный ресурс] / И. Гаранья // Режим доступа: <http://lexandbusiness.ru/view-article.php?id=1319>.

4. Лозова О.А. Аналіз сучасних тенденцій розвитку міжнародного туризму [Электронный peсурс] / Лозова O.A. // Режим доступа: <http://khntusg. com.ua/ files/sbornik/vestnik_125/29.pdf>.

5. Полещук Н.И. Основные тенденции развития международного туризма / Н.И. Полещук // Научный сборник Белорусского государственного университета. 2012. Вып. III. C.176-179. 
6. Чернецкая С.А. Современные тенденции развития международного туризма / С.А. Чернецкая // Культура народов Причерноморья. 2012. №232. С. 85-88.

7. Адамеску А.А. Экономические и организационные аспекты интеграции российской туристской индустрии в систему международного туризма / А.А. Адамеску, В.Ю. Воскресенский // Региональная экономика: теория и практика. 2011. № 11 (194). С. 5359.

8. Артемова Е.И. Международный опыт управления в сфере продвижения и развития туризма [Электронный режим] / Е.И. Артемова, Н.А. Цапенко // Научный журнал КубГАУ. 2013. №92(o8). - Режим доступа: <http://ej.kubagro.ru/2013/o8/pdf/26.pdf>.

9. World Tourism Organization UNWTO [Электронный ресурс] // Режим доступа: $<$ http://www2.unwto.org/>.

10. Vetitnev A.M., Kontorskih A.P. An Analysis of Current Approaches to Defining the Term “Tourist Destination” // Tourism Education Studies and Practice, 2014, Vol.(3), № 3, pp. 121-128.

\section{References:}

1. Radnaev S.B. Mezhdunarodnyi turizm $\mathrm{v}$ sisteme sovremennykh mezhdunarodnykh ekonomicheskikh otnoshenii / S.B. Radnaev; dis. ... kand. ekon. nauk: 08.00.14. Moskva, 2001. $159 \mathrm{~s}$.

2. Ponomareva S.Yu. Mezhdunarodnyi turizm kak forma vneshneekonomicheskoi deyatel'nosti regiona (na primere Rostovskoi oblasti) / S.Yu. Ponomareva; dis. ... kand. ekon. nauk: 08.00.14. Rostov-na-Donu, 2004. 205 s.

3. Garan'ya I. Tendentsii razvitiya mezhdunarodnogo turizma [Elektronnyi resurs] / I. Garan'ya // Rezhim dostupa: <http://lexandbusiness.ru/view-article.php?id=1319>.

4. Lozova O.A. Analiz suchasnikh tendentsii rozvitku mizhnarodnogo turizmu [Elektronnyi resurs] / Lozova O.A. // Rezhim dostupa: <http://khntusg.com.ua/files/ sbornik /vestnik_ 125/29.pdf>.

5. Poleshchuk N.I. Osnovnye tendentsii razvitiya mezhdunarodnogo turizma / N.I. Poleshchuk // Nauchnyi sbornik Belorusskogo gosudarstvennogo universiteta. 2012. Vyp. III. S.176-179.

6. Chernetskaya S.A. Sovremennye tendentsii razvitiya mezhdunarodnogo turizma / S.A. Chernetskaya // Kul'tura narodov Prichernomor'ya. 2012. №232. S. 85-88.

7. Adamesku A.A. Ekonomicheskie i organizatsionnye aspekty integratsii rossiiskoi turistskoi industrii $\mathrm{v}$ sistemu mezhdunarodnogo turizma / A.A. Adamesku, V.Yu. Voskresenskii // Regional'naya ekonomika: teoriya i praktika. 2011. № 11 (194). S. 53-59.

8. Artemova E.I. Mezhdunarodnyi opyt upravleniya v sfere prodvizheniya i razvitiya turizma [Elektronnyi rezhim] / E.I. Artemova, N.A. Tsapenko // Nauchnyi zhurnal KubGAU. 2013. №92(o8). - Rezhim dostupa: <http://ej.kubagro.ru/2013/o8/pdf/26.pdf>.

9. World Tourism Organization UNWTO [Elektronnyi resurs] // Rezhim dostupa: $<$ http://www2.unwto.org/>.

10. Vetitnev A.M., Kontorskih A.P. An Analysis of Current Approaches to Defining the Term “Tourist Destination” // Tourism Education Studies and Practice, 2014, Vol.(3), № 3, pp. 121-128.

УдК 338.48

\section{Тенденции развития международного туризма и императивы модернизации туристической индустрии}

Зейнеб Османовна Адаманова

Крымский инженерно-педагогический университет экономики, Российская Федерация 295015, Республика Крым, г. Симферополь, ул. Севастопольская, пер. Учебный, 8 Доктор экономических наук, профессор

E-mail: azo2005edie@mail.ru 
Аннотация. В статье обоснована значимость и выделены особенности международного туризма. Установлено, что данная отрасль мировой экономики развивается достаточно устойчиво при сохранении значительных различий по регионам мира. Выделены группы стимулирующих факторов и основные тенденции развития международного туризма на современном этапе, в том числе качественные изменения в туристическом продукте и функционировании мирового рынка туристических услуг. Определены императивы модернизации туристической индустрии на национальном уровне.

Ключевые слова: международный туризм; туристическая индустрия. 